\title{
Aging, Output Per Capita, and Secular Stagnation
}

\author{
Gauti B. Eggertsson, Manuel Lancastre, and Lawrence H. Summers.1
}

December 9, 2018

\section{ONLINE APPENDIX}

Appendix 1: Tables

Appendix 2: Model 
APPENDIX 1 - TABLES

Table A1: Estimates of the impact of aging on GDP per capita from 1990 to 2014: old > 50 years

\begin{tabular}{|c|c|c|c|c|c|}
\hline & $\begin{array}{c}(1) \\
1990-2014 \\
\end{array}$ & $\begin{array}{c}(2) \\
1990-2008 \\
\end{array}$ & $\begin{array}{c}(3) \\
2008-2014 \\
\end{array}$ & $\begin{aligned} & (4) \\
\approx & \mathrm{ZLB}\end{aligned}$ & 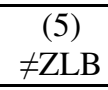 \\
\hline $\begin{array}{l}\text { Change of the ratio } \\
\text { of old to young }\end{array}$ & $\begin{array}{l}0.361 * \\
(0.208)\end{array}$ & $\begin{array}{c}0.784 * * * \\
(0.282)\end{array}$ & $\begin{array}{c}-0.528 * * \\
(0.205)\end{array}$ & $\begin{array}{l}-0.429 \\
(0.320)\end{array}$ & $\begin{array}{l}-0.302 \\
(0.310)\end{array}$ \\
\hline $\begin{array}{l}\text { Observations } \\
\text { R-squared }\end{array}$ & $\begin{array}{c}168 \\
0.019\end{array}$ & $\begin{array}{c}168 \\
0.052\end{array}$ & $\begin{array}{c}168 \\
0.038\end{array}$ & $\begin{array}{c}55 \\
0.038\end{array}$ & $\begin{array}{c}113 \\
0.008\end{array}$ \\
\hline
\end{tabular}

Table A2: Estimates of the impact of aging on GDP per capita: old $>50$ years

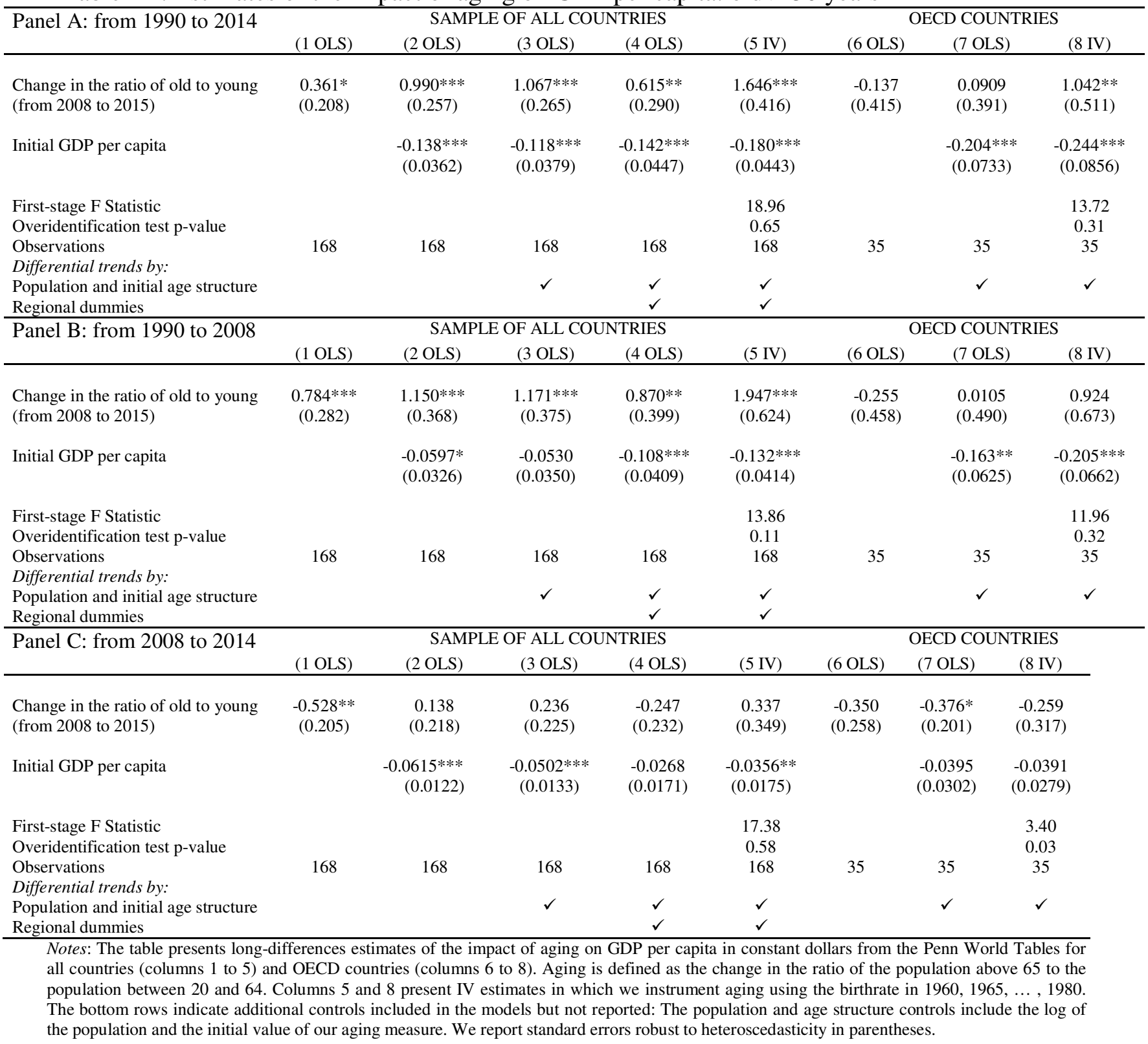


Table A3: Estimates of the impact of Labor Input on GDP per capita: old $>65$ years

\begin{tabular}{lccccc}
\hline & $(1)$ & $(2)$ & $(3)$ & $(4)$ & $(5)$ \\
& $1990-2014$ & $1990-2008$ & $2008-2014$ & $\approx$ ZLB & $\neq$ ZLB \\
\hline Change in labor input & $-1.827^{*}$ & $-3.297^{* *}$ & $3.260^{* * *}$ & $3.180^{* * *}$ & 1.620 \\
& $(1.084)$ & $(1.419)$ & $(1.005)$ & $(1.501)$ & $(1.680)$ \\
Observations & 168 & 168 & 168 & 55 & 113 \\
R-squared & 0.019 & 0.052 & 0.038 & 0.067 & 0.007 \\
\hline \multicolumn{7}{c}{ Robust standard errors in parentheses } \\
$* * * \mathrm{p}<0.01, * * \mathrm{p}<0.05, * \mathrm{p}<0.1$
\end{tabular}

Table A4: Estimates of the impact of Labor Input on GDP per capita: old > 65 years

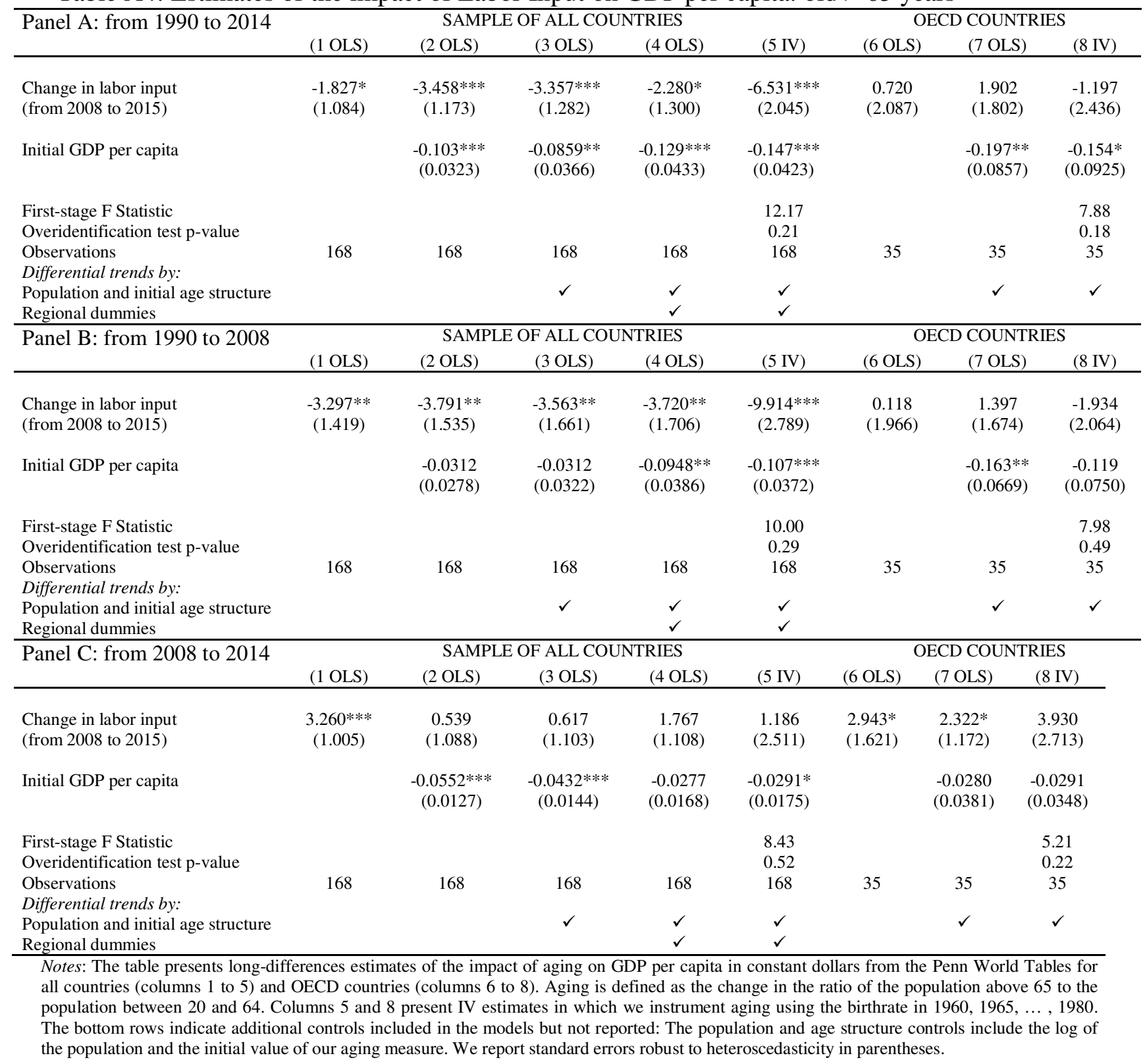


Table A5: Estimates of the impact of Labor Input Ratio on GDP per adult: old $>65$ years

\begin{tabular}{lccccc}
\hline & $(1)$ & $(2)$ & $(3)$ & $(4)$ & $(5)$ \\
& $1990-2014$ & $1990-2008$ & $2008-2014$ & $\approx$ ZLB & $\neq$ ZLB \\
\hline Change in labor input & $-2.014 *$ & $-3.235^{* *}$ & $2.681^{* * *}$ & $2.425^{*}$ & 1.361 \\
& $(1.031)$ & $(1.365)$ & $(1.018)$ & $(1.386)$ & $(1.737)$ \\
& & & & & \\
Observations & 168 & 168 & 168 & 55 & 113 \\
R-squared & 0.019 & 0.052 & 0.038 & 0.046 & 0.005 \\
\hline \multicolumn{5}{c}{ Robust standard errors in parentheses } \\
& $* * * \mathrm{p}<0.01, * * \mathrm{p}<0.05, * \mathrm{p}<0.1$ & &
\end{tabular}

Table A6: Estimates of the impact of Labor Input on GDP per adult: old $>65$ years

\begin{tabular}{|c|c|c|c|c|c|c|c|c|}
\hline \multirow{2}{*}{ Panel A: from 1990 to 2014} & \multicolumn{5}{|c|}{ SAMPLE OF ALL COUNTRIES } & \multicolumn{3}{|c|}{ OECD COUNTRIES } \\
\hline & $(1 \mathrm{OLS})$ & $(2 \mathrm{OLS})$ & (3 OLS) & $(4 \mathrm{OLS})$ & $(5 \mathrm{IV})$ & $(6 \mathrm{OLS})$ & (7 OLS) & $(8 \mathrm{IV})$ \\
\hline $\begin{array}{l}\text { Change in labor input } \\
\text { (from } 2008 \text { to 2015) }\end{array}$ & $\begin{array}{l}-2.014 * \\
(1.031)\end{array}$ & $\begin{array}{c}-3.487 * * * \\
(1.042)\end{array}$ & $\begin{array}{c}-2.979 * * \\
(1.169)\end{array}$ & $\begin{array}{l}-2.144 * \\
(1.232)\end{array}$ & $\begin{array}{c}-6.082 * * * \\
(1.887)\end{array}$ & $\begin{array}{l}0.970 \\
(1.821)\end{array}$ & $\begin{array}{c}1.995 \\
(1.770)\end{array}$ & $\begin{array}{l}-1.310 \\
(2.516)\end{array}$ \\
\hline Initial GDP per adult & & $\begin{array}{c}-0.132 * * * \\
(0.0348)\end{array}$ & $\begin{array}{c}-0.128 * * * \\
(0.0375)\end{array}$ & $\begin{array}{c}-0.149 * * * \\
(0.0442)\end{array}$ & $\begin{array}{c}-0.159 * * * \\
(0.0424)\end{array}$ & & $\begin{array}{r}-0.161 * \\
(0.0922)\end{array}$ & $\begin{array}{l}-0.0827 \\
(0.105)\end{array}$ \\
\hline $\begin{array}{l}\text { First-stage F Statistic } \\
\text { Overidentification test p-value } \\
\text { Observations } \\
\text { Differential trends by: } \\
\text { Population and initial age structure } \\
\text { Regional dummies } \\
\end{array}$ & 168 & 168 & $\begin{array}{c}168 \\
\checkmark\end{array}$ & $\begin{array}{c}168 \\
\checkmark \\
\checkmark \\
\end{array}$ & $\begin{array}{l}12.61 \\
0.50 \\
168 \\
\checkmark \\
\checkmark \\
\end{array}$ & 35 & $\begin{array}{l}35 \\
\checkmark\end{array}$ & $\begin{array}{c}6.61 \\
0.13 \\
35 \\
\checkmark\end{array}$ \\
\hline Panel B: from 1990 to 2008 & (1 OLS) & $\begin{array}{l}\text { SAMPL } \\
(2 \mathrm{OLS}) \\
\end{array}$ & $\begin{array}{l}\text { F ALL COU } \\
(3 \mathrm{OLS}) \\
\end{array}$ & $\begin{array}{l}\text { TRIES } \\
(4 \text { OLS }) \\
\end{array}$ & $(5 \mathrm{IV})$ & $\begin{array}{r}\mathrm{OF} \\
(6 \mathrm{OLS}) \\
\end{array}$ & $\begin{array}{r}\text { ECD COUNT } \\
(7 \text { OLS }) \\
\end{array}$ & $\begin{array}{l}\text { TRIES } \\
(8 \mathrm{IV}) \\
\end{array}$ \\
\hline $\begin{array}{l}\text { Change in labor input } \\
\text { (from } 2008 \text { to 2015) }\end{array}$ & $\begin{array}{c}-3.235^{* *} \\
(1.365)\end{array}$ & $\begin{array}{c}-3.803 * * * \\
(1.406)\end{array}$ & $\begin{array}{c}-3.141 * * \\
(1.532)\end{array}$ & $\begin{array}{c}-3.448 * * \\
(1.623)\end{array}$ & $\begin{array}{l}-8.890 * * * \\
(2.598)\end{array}$ & $\begin{array}{c}0.454 \\
(1.622)\end{array}$ & $\begin{array}{c}1.386 \\
(1.541)\end{array}$ & $\begin{array}{l}-2.414 \\
(2.095)\end{array}$ \\
\hline Initial GDP per adult & & $\begin{array}{c}-0.0550 * \\
(0.0306)\end{array}$ & $\begin{array}{c}-0.0685^{* *} \\
(0.0330)\end{array}$ & $\begin{array}{c}-0.117 * * * \\
(0.0395)\end{array}$ & $\begin{array}{c}-0.120 * * * \\
(0.0371)\end{array}$ & & $\begin{array}{c}-0.124 \\
(0.0737)\end{array}$ & $\begin{array}{l}-0.0396 \\
(0.0878\end{array}$ \\
\hline $\begin{array}{l}\text { First-stage F Statistic } \\
\text { Overidentification test p-value } \\
\text { Observations } \\
\text { Differential trends by: } \\
\text { Population and initial age structure } \\
\text { Regional dummies }\end{array}$ & 168 & 168 & $\begin{array}{c}168 \\
\checkmark\end{array}$ & $\begin{array}{c}168 \\
\checkmark \\
\checkmark \\
\end{array}$ & $\begin{array}{l}10.31 \\
0.71 \\
168 \\
\\
\checkmark \\
\checkmark \\
\end{array}$ & 35 & $\begin{array}{l}35 \\
\checkmark\end{array}$ & $\begin{array}{c}6.84 \\
0.38 \\
35 \\
\checkmark\end{array}$ \\
\hline Panel C: from 2008 to 2014 & $(1 \mathrm{OLS})$ & $\begin{array}{l}\text { SAMPL } \\
(2 \mathrm{OLS}) \\
\end{array}$ & $\begin{array}{l}\text { F ALL COU } \\
(3 \text { OLS }) \\
\end{array}$ & $\begin{array}{l}\text { TRIES } \\
(4 \text { OLS }) \\
\end{array}$ & $(5 \mathrm{IV})$ & $(6 \mathrm{OLS})^{\mathrm{OI}}$ & $\begin{array}{l}\text { ECD COUNT } \\
(7 \text { OLS })\end{array}$ & $\begin{array}{l}\text { TRIES } \\
(8 \mathrm{IV}) \\
\end{array}$ \\
\hline $\begin{array}{l}\text { Change in labor input } \\
\text { (from } 2008 \text { to 2015) }\end{array}$ & $\begin{array}{c}2.681 * * * \\
(1.018)\end{array}$ & $\begin{array}{c}0.386 \\
(1.077)\end{array}$ & $\begin{array}{c}0.501 \\
(1.101)\end{array}$ & $\begin{array}{l}1.355 \\
(1.089)\end{array}$ & $\begin{array}{c}0.349 \\
(2.406)\end{array}$ & $\begin{array}{l}2.678^{*} \\
(1.498)\end{array}$ & $\begin{array}{l}2.242^{*} \\
(1.155)\end{array}$ & $\begin{array}{c}4.194 \\
(2.684)\end{array}$ \\
\hline Initial GDP per adult & & $\begin{array}{c}-0.0608^{* * * *} \\
(0.0143)\end{array}$ & $\begin{array}{c}-0.0498^{* * * *} \\
(0.0157)\end{array}$ & $\begin{array}{c}-0.0265 \\
(0.0181)\end{array}$ & $\begin{array}{c}-0.0284 \\
(0.0182)\end{array}$ & & $\begin{array}{c}-0.0235 \\
(0.0401)\end{array}$ & $\begin{array}{c}-0.0262 \\
(0.0364)\end{array}$ \\
\hline $\begin{array}{l}\text { First-stage F Statistic } \\
\text { Overidentification test p-value } \\
\text { Observations } \\
\text { Differential trends by: } \\
\text { Population and initial age structure } \\
\text { Regional dummies }\end{array}$ & 168 & 168 & $\begin{array}{c}168 \\
\checkmark\end{array}$ & $\begin{array}{c}168 \\
\checkmark \\
\checkmark \\
\end{array}$ & $\begin{array}{l}8.85 \\
0.59 \\
168 \\
\\
\checkmark \\
\checkmark \\
\end{array}$ & 35 & $\begin{array}{l}35 \\
\checkmark\end{array}$ & $\begin{array}{c}5.06 \\
0.25 \\
35 \\
\checkmark\end{array}$ \\
\hline
\end{tabular}


Table A7: Estimates of the impact of aging on GDP per capita from 1990 to 2014: old > 65 years Panel A: in non OECD countries

(2)

(3)

(4) (5)

1990-2015 1990-2008 2008-2015 $\approx$ ZLB $\neq$ ZLB

Change of the ratio of old to young

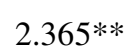

(1.026)

$3.208^{* *}$

(1.422)

133

Observations R-squared 0.045
133 0.056

$-0.854$

(0.862)

133

0.006
$-0.274$

(1.247)

$-1.046$

(1.242)

106 0.001 0.006

Panel B: Excluding countries in the periphery of the European:

Portugal, Italy, Ireland, Greece, and Spain

(1)

1990-2015
(2) 1990-2008
(3) 2008-2015
$-1.795^{* * *}$

(0.533)

(0.708)
$2.230 * *$

$(1.024)$
164 0.014
164 0.042

$\begin{array}{cc}4 & 164 \\ 4 & 0.042\end{array}$

164

0.049

$(4)$ $\approx$ ZLB $\neq$ ZLB

Robust standard errors in parentheses $* * * \mathrm{p}<0.01, * * \mathrm{p}<0.05, * \mathrm{p}<0.1$

Table A8: Estimates of the impact of aging on GDP per capita from 2008 to 2014 for different values of ZLB threshold: old $>65$ years

\begin{tabular}{|c|c|c|c|c|c|c|c|c|}
\hline \multirow[t]{3}{*}{ ZLB Threshold } & $0.5 \%$ & $0.5 \%$ & $1.0 \%$ & $1.0 \%$ & $1.5 \%$ & $1.5 \%$ & $2.0 \%$ & $2.0 \%$ \\
\hline & (1) & (2) & (3) & (4) & (5) & $(6)$ & (7) & (8) \\
\hline & $\approx$ ZLB & $\neq \mathrm{ZLB}$ & $\approx \mathrm{ZLB}$ & $\neq \mathrm{ZLB}$ & $\approx$ ZLB & $\neq \mathrm{ZLB}$ & $\approx \mathrm{ZLB}$ & $\neq \mathrm{ZLB}$ \\
\hline Change of the ratio & $-1.527 * *$ & $-1.451 *$ & $-1.640^{*}$ & -1.131 & $-1.843^{* *}$ & -1.099 & $-1.948 * * *$ & -1.248 \\
\hline of old to young & $(0.723)$ & $(0.874)$ & $(0.815)$ & $(0.969)$ & $(0.761)$ & $(1.010)$ & $(0.671)$ & $(1.090)$ \\
\hline Observations & 42 & 126 & 48 & 120 & 55 & 113 & 63 & 105 \\
\hline R-squared & 0.075 & 0.017 & 0.075 & 0.010 & 0.093 & 0.009 & 0.107 & 0.010 \\
\hline
\end{tabular}


Table A9: Estimates of the impact of aging on capital per worker, through real interest rates Panel A: Estimates of the impact of aging on Capital per working age adult (age 20-65)

(1)

(2)

(3)

(4)

(5)

$1990-2014$

$1990-2008$

2008-2014

$\approx \mathrm{ZLB}$

$\neq$ ZLB

Change of the ratio

$2.688 * * *$

$3.298 * *$

0.598

$-1.100$

1.742

of old to young

(0.920)

(1.260)

(0.753)

(1.075)

(1.709)

Observations

$59 \quad 59$

0.068

59

16

43

R-squared

0.066

0.004

0.036

0.016

Panel B: Estimates of the impact of aging on real interest rate

(1)

(2)

(3)

(4)

(5)

1990-2014

1990-2008

2008-2014

$\approx \mathrm{ZLB}$

$\neq$ ZLB

Change of the ratio

$-0.587 * *$

$-0.537$

(0.230)

(0.323)

$-0.489$

(0.353)

$-0.409$

$-0.824$

of old to young

59

59

59

(0.390)

(0.842)

Observations

0.024

0.009

0.024

16

43

R-squared

terest

(2)

Panel C: Estimates of the impact

1990-2008

(3)

0.048

0.027 1990-2014

2008-2014

(4)

$\approx$ ZLB

(5)

$\neq \mathrm{ZLB}$

Change of real

$-0.846 * * *$
$(0.253)$

$-0.706 * * *$

0.0929

(0.211)

(0.365)

$-0.681$

0.218

interest rate

59
0.095

59

59

(0.648)

(0.403)

Observations

0.095

0.104

0.001

16

43

Notes: Robust standard errors in parentheses, ${ }^{* * *} \mathrm{p}<0.01,{ }^{* *} \mathrm{p}<0.05, * \mathrm{p}<0.1$. The table presents in Panel A long-differences estimates of the impact of aging on capital per working age adult in constant dollars from the Penn World Tables in countries for which real interest rate data from the World Bank exists between 1990 and 2015. Panel B presents long-differences estimates of the impact of aging on real interest rates data from the World Bank. Real interest rates are defined as lending interest rates adjusted for inflation as measured by the GDP deflator. Panel C presents long-differences estimates of the impact of real interest rates on capital per working age adult . 


\section{APPENDIX 2 - MODEL}

This appendix summarizes the microfoundations of the simple general equilibrium model of section 4.

\section{A Households}

Individuals live for two periods, young and old, and maximize utility from consumption of one aggregate good according to:

$$
\begin{aligned}
U_{t}\left(c_{t}^{y}, c_{t+1}^{o}\right) & =\max _{c_{t}^{y}, c_{t+1}^{o}} \mathbb{E}_{t}\left\{u\left(c_{t}^{y}\right)+\beta u\left(c_{t+1}^{o}\right)\right\} \\
\text { s.t. } c_{t}^{y} & =w_{t} l_{t}-\tau_{t}-s_{t} \\
c_{t+1}^{o} & =\frac{\left(1+i_{t}\right)}{\prod_{t+1}} s_{t}
\end{aligned}
$$

where the $u(c)=\frac{c^{1-\sigma}}{1-\sigma}$ is a constant relative risk aversion (CRRA) preference function. $c_{t}^{y}$ and $c_{t+1}^{o}$ are household's consumption respectively when young and old. When young, individuals earn income in period $t$ by renting their labor endowment $l_{t}$ to firms at wage $w_{t}$. After paying taxes $\tau_{t}$ the young use their net income to consume in period $t$ and to save $s_{t}$ for consumption when old by accumulation of private capital supplied to firms for production during the next period for a gross real rent $\frac{\left(1+i_{t}\right)}{\Pi_{t+1}}$, such that:

$$
K_{t+1}^{s}=N_{t}^{y} s_{t}
$$

where $N_{t}^{y}$ is the size of young generation at time $t$. When old, individuals dissave to consume, earning a gross real return $\frac{\left(1+i_{t}\right)}{\Pi_{t+1}}$ on their savings from previous period (3). We derive the first order conditions of this problem by maximizing the Lagrangian ${ }^{1}$ :

$$
\mathcal{L}_{t}=u\left(c_{t}^{y}\right)+\beta u\left(c_{t+1}^{o}\right)-\lambda_{t}\left(c_{t}^{y}-w_{t} l_{t}+\tau_{t}+s_{t}\right)-\lambda_{t+1}\left(c_{t+1}^{o}-\frac{\left(1+i_{t}\right)}{\prod_{t+1}} s_{t}\right)
$$

First-order conditions:

$$
\begin{aligned}
\frac{\delta \mathcal{L}_{t}}{\delta c_{t}^{y}} & =u_{c}\left(c_{t}^{y}\right)-\lambda_{t}=0 \\
\frac{\delta \mathcal{L}_{t}}{\delta c_{t+1}^{o}} & =\beta u_{c}\left(c_{t}^{o}\right)-\lambda_{t+1}=0 \\
\frac{\delta \mathcal{L}_{t}}{\delta k_{t+1}^{s}} & =-\lambda_{t}+\lambda_{t+1} \frac{\left(1+i_{t}\right)}{\Pi_{t+1}}=0
\end{aligned}
$$

Perfect foresight young individuals are at an interior solution and their consumption-saving choices satisfy a standard Euler equation given by

$$
\lambda_{t}=\lambda_{t+1} \frac{\left(1+i_{t}\right)}{\prod_{t+1}} \rightarrow u_{c}\left(c_{t}^{y}\right)=\beta R_{t} u_{c}\left(c_{t}^{o}\right) \Leftrightarrow \frac{1}{\left(c_{t}^{y}\right)^{\sigma}}=\beta \frac{\left(1+i_{t}\right)}{\prod_{t+1}} \frac{1}{\left(c_{t+1}^{o}\right)^{\sigma}}
$$

\footnotetext{
${ }^{1}$ The expectations operator is ignored since the model is deterministic.
} 
Let $R_{t} \equiv \frac{\left(1+i_{t}\right)}{\Pi_{t+1}} \equiv 1+r_{t}$. Then the previous expression can be written as

$$
\frac{1}{c_{t}^{y}}=\beta_{R_{t}, \sigma} R_{t} \frac{1}{c_{t+1}^{o}} \Leftrightarrow c_{t+1}^{o}=R_{t}\left[\beta_{R_{t}, \sigma} c_{t}^{y}\right]
$$

where $\beta_{R_{t}, \sigma}=\beta^{\frac{1}{\sigma}} R_{t}^{\frac{1-\sigma}{\sigma}} \stackrel{(\sigma=1)}{=} \beta$. Directly from the budget constraint of the old(3) we have

$$
s_{t}=\beta_{R_{t}, \sigma} c_{t}^{y}
$$

Savings of the young $s_{t}$ can then be derived by replacing the previous expression of $c_{t}^{y}$ with respect to $s_{t}$ in the budget constraint of the young(2):

$$
s_{t}=\frac{\beta_{R_{t}, \sigma}}{1+\beta_{R_{t}, \sigma}}\left(w_{t} l_{t}-\tau_{t}\right)
$$

\section{Capital supply:}

Because aggregate savings in period $t$ is equal to the capital supplied in the following period, we have:

$$
N_{t}^{y} s_{t}=K_{t+1}^{s} \Leftrightarrow s_{t}=\frac{K_{t+1}^{s}}{N_{t}^{y}}=\frac{K_{t+1}^{s}}{N_{t+1}^{y}} \frac{N_{t+1}^{y}}{N_{t}^{y}}=k_{t+1}^{s}\left(1+g_{t}^{y}\right)=\frac{k_{t+1}^{s}}{A_{t}} \Rightarrow k_{t+1}^{s}=A_{t} s_{t}
$$

where $k_{t}^{s}$ is capital supplied per young individual at time $t, 1+g_{t}^{y}=N_{t+1}^{y} / N_{t}^{y}$ is the birth rate of the young, and defining an aging parameter as the ratio of old to young at time $t+1$ :

$$
A_{t}=\frac{N_{t+1}^{o}}{N_{t+1}^{y}}=\frac{N_{t}^{y}}{N_{t+1}^{y}}=\frac{1}{1+g_{t}^{y}}
$$

Then,

$$
k_{t+1}^{s}=A_{t} s_{t}=A_{t} \frac{\beta_{R_{t}, \sigma}}{1+\beta_{R_{t}, \sigma}}\left(w_{t} l_{t}-\tau_{t}\right)
$$

\section{No-arbitrage condition:}

The return on savings $R_{t}$ accounts for the rent $R_{t+1}^{k}$ on capital firms pay to individuals, and a capital depreciation $\delta$. So, the budget constraint of the old can alternatively be expressed by:

$$
c_{t+1}^{o}=\frac{1}{A_{t+1}}\left[(1-\delta) k_{t+1}^{s}+R_{t+1}^{k} k_{t+1}^{s}\right]=s_{t}\left(1-\delta+r_{t+1}^{k}\right)
$$

Implying the following no-arbitrage condition:

$$
R_{t+1}^{k}=R_{t}+\delta-1
$$




\section{B Firms}

We assume that firms produce only one good, are perfectly competitive, and take prices as given. They hire labor at a wage $w_{t}$ and rent capital at rate $r_{t}^{k}$ to maximize period-by-period profits. They operate using a standard Cobb-Douglas production function, and their problem is given by:

$$
\begin{aligned}
& \max _{L_{t}, K_{t}} P_{t} Y_{t}-W_{t} L_{t}-P_{t} R_{t}^{k} K_{t} \\
& \text { s.t. } Y_{t}=L_{t}^{1-\alpha} K_{t}^{\alpha}
\end{aligned}
$$

The firm's capital and labor demand equilibrium conditions are given by:

$$
\begin{aligned}
R_{t}^{k} & =\alpha \frac{Y_{t}}{K_{t}} \\
w_{t} & =\frac{W_{t}}{P_{t}}=(1-\alpha) \frac{Y_{t}}{L_{t}}
\end{aligned}
$$

Each individual of the young generation supplies his labor endowment inelastically at $\bar{l}$. Since for now we are assuming wages are flexible, and full-employment, then $L_{t}=N_{t}^{y} \bar{l}$. Let $k_{t}^{d}=\frac{K_{t}}{N_{t}^{y}}=\frac{K_{t}}{L_{t}} \bar{l}$. Then:

$$
\begin{aligned}
& w_{t}=(1-\alpha)\left(\frac{\alpha}{R_{t}^{k}}\right)^{\frac{\alpha}{1-\alpha}} \\
& k_{t}^{d}=\bar{l}\left(\frac{\alpha}{R_{t}^{k}}\right)^{\frac{1}{1-\alpha}}
\end{aligned}
$$

Defining $\tilde{x} \equiv \ln x$ :

$$
\tilde{k}_{t+1}^{d}=\ln \left[\bar{l}^{\frac{1}{1-\alpha}}\right]-\frac{1}{1-\alpha} \tilde{R}_{t+1}^{k}
$$

\section{Government}

We assume the Government budget is balanced, $G_{t}=T_{t}$. And that Government spending is exogenously proportional to full-employment output $G_{t}=\Omega \bar{Y}_{t}$.

$$
\begin{aligned}
G_{t} & =\mathcal{G} \bar{Y}_{t}=T_{t}=N_{t}^{y} \tau_{t} \\
\tau_{t} & =\frac{\mathcal{G}}{N_{t}^{y}} \bar{Y}_{t}=\frac{\mathcal{G}}{N_{t}^{y}} \frac{w_{t} \bar{L}_{t}}{1-\alpha}=w_{t} \bar{l} \frac{\mathcal{G}}{1-\alpha}=w_{t} \bar{l} \tau \\
\text { where } \tau & =\frac{\mathcal{G}}{1-\alpha} \text { is exogenously determined. }
\end{aligned}
$$

Capital supply per young individual can then be expressed by:

$$
k_{t+1}^{s}=A_{t} \frac{\beta_{R_{t}, \sigma}}{1+\beta_{R_{t}, \sigma}} w_{t} \bar{l}\left(\mu_{t}-\tau\right), \text { where } \mu_{t}=l_{t} / \bar{l} \stackrel{\left(l_{t}=\bar{l}_{t}\right)}{=} 1
$$


$\mu_{t}$ is the employment ratio of the young, equal to 1 for now. Replacing $w_{t}$ by (22) and taking logs the previous expression becomes:

$$
\tilde{k}_{t+1}^{s}=\ln \left[\bar{l}(1-\tau)(1-\alpha) \alpha^{\frac{\alpha}{1-\alpha}}\right]+\ln \left(\frac{\beta_{R_{t}, \sigma}}{1+\beta_{R_{t}, \sigma}}\right)-\frac{\alpha}{1-\alpha} \tilde{R}_{t}^{k}+\tilde{A}_{t}
$$

\section{Comparative statics}

Without loss of generality we assume full depreciation of capital in one period $\delta=1 \Rightarrow R_{t}=$ $R_{t+1}^{k}$. Assuming the system is on a steady state equilibrium where $R_{t}=R$,

$$
\tilde{k}^{d}=\tilde{k}^{s}
$$

where,from (24) and (29)

$$
\begin{aligned}
& \tilde{k}^{d}=-\frac{1}{1-\alpha} \tilde{R}+\ln \left[\bar{l} \alpha^{\frac{1}{1-\alpha}}\right] \\
& \tilde{k}^{s}=-\frac{\alpha}{1-\alpha} \tilde{R}+\tilde{A}+\ln \left(\frac{\beta_{R, \sigma}}{1+\beta_{R, \sigma}}\right)+\ln \left[\bar{l}(1-\tau)(1-\alpha) \alpha^{\frac{\alpha}{1-\alpha}}\right]
\end{aligned}
$$

(i) If $\sigma=1$ then $\beta_{R, \sigma}=\beta$ and $\tilde{R}$ and $\tilde{k}$ has the following closed form expression

$$
\begin{aligned}
& \tilde{R}=-\tilde{A}+\ln \left[\left(\frac{1+\beta}{\beta}\right)\left(\frac{\alpha}{1-\alpha}\right)\left(\frac{1}{1-\tau}\right)\right] \\
& \tilde{k}=\frac{1}{1-\alpha} \tilde{A}+\frac{1}{1-\alpha} \ln \left[\left(\frac{1+\beta}{\beta}\right)\left(\frac{\alpha}{1-\alpha}\right)\left(\frac{1}{1-\tau}\right)\right]+\ln \left[\bar{l} \alpha^{\frac{1}{1-\alpha}}\right]
\end{aligned}
$$

(ln)Aging $\tilde{A}$ has a one for one negative impact on $\tilde{R}$

$$
\frac{d \tilde{R}}{d \tilde{A}}=-1
$$

(ii) For the general case where $\sigma>0$ we can use the Theorem of the Implicit Function to express the former derivative

$$
\frac{d \tilde{R}}{d \tilde{A}}=-\frac{1+\beta_{R, \sigma}}{\frac{1}{\sigma}+\beta_{R, \sigma}}<0
$$

which is still negative (and equal to -1 when $\sigma=1$ ). Also, aging has a stronger impact on real rates when the Relative Risk Aversion $\sigma$ is higher. Aging expands the supply of capital which effect has to be offset by a reduction of the real rate in order to sustain a general equilibrium. This real rate change has to be higher if the Elasticity of Intertemporal Substution is lower (or $\sigma$ higher). This is consistent with the data used.

(iii) Impact of aging on output per capita $\tilde{y}^{p c}$

Let,

$$
y_{t}=\frac{Y_{t}}{N_{t}^{y}}=\left(\frac{K_{t}}{N_{t}^{y}}\right)^{\alpha} \Rightarrow \tilde{y}_{t}=\alpha \tilde{k}_{t}
$$


Since we are assuming full-employment $L_{t}=N_{t}^{y}$. Then,

$$
y_{t}^{p c}=\frac{Y_{t}}{N_{t}^{y}+N_{t}^{o}}=\frac{Y_{t}}{N_{t}^{y}} \frac{N_{t}^{y}}{N_{t}^{y}+N_{t}^{o}}=\frac{Y_{t}}{N_{t}^{y}} \frac{1}{1+\frac{N_{t}^{o}}{N_{t}^{y}}}=y_{t} \frac{1}{1+A_{t-1}}
$$

using logs,

$$
\tilde{y}_{t}^{p c}=\tilde{y}_{t}-\ln \left(1+A_{t-1}\right)
$$

replacing $\tilde{y}_{t}=\alpha \tilde{k}_{t}$

$$
\tilde{y}_{t}^{p c}=\alpha \tilde{k}_{t}-\ln \left(1+A_{t-1}\right)
$$

now replacing $\tilde{k}_{t}^{d}=\ln \left[\bar{l} \alpha^{\frac{1}{1-\alpha}}\right]-\frac{1}{1-\alpha} \tilde{R}_{t}$

$$
\tilde{y}_{t}^{p c}=-\frac{\alpha}{1-\alpha} \tilde{R}_{t}-\ln \left(1+A_{t-1}\right)+\alpha \ln \left[\bar{l}^{\frac{1}{1-\alpha}}\right]
$$

Finally by replacing $\tilde{R}$ by its steady state expression and taking the derivative of $\tilde{y}_{t}^{p c}$ with respect to $\tilde{A}$

$$
\frac{d y^{\tilde{p} c}}{d \tilde{A}}=\left(\frac{\alpha}{1-\alpha}\right)\left(\frac{1+\beta_{R, \sigma}}{\frac{1}{\sigma}+\beta_{R, \sigma}}\right)-\left(\frac{A}{1+A}\right)
$$

The first term of the expression is the capital deepening effect of aging which is positive, and the second one is the negative demographic effect of aging. Aging has a positive impact on output per capita when the capital deepening effect prevail over the demographic effect:

$$
\frac{d y^{\tilde{p} c}}{d \tilde{A}}>0 \Leftrightarrow\left(\frac{\alpha}{1-\alpha}\right)\left(\frac{1+\beta_{R, \sigma}}{\frac{1}{\sigma}+\beta_{R, \sigma}}\right)>\left(\frac{A}{1+A}\right)
$$

We see directly from this expression that for greater values of $\sigma$ the capital deepening effect is stronger, such that we would expect a stronger positive impact of aging on output per capita in those countries. Note also that the demographic effect $\frac{A}{1+A}=\frac{N^{o}}{N^{y}+N^{o}}$, so in countries where people live longer we would expect a weaker positive relation between aging and output per capita. This is suggested by the data where the significance of the results for OECD countries is much weaker.

\section{E Transition dynamics}

Define

$$
\begin{aligned}
& \tilde{x}^{*} \equiv \text { steady state of } \ln (x) \\
& \hat{x}_{t} \equiv \tilde{x}-\tilde{x}^{*}
\end{aligned}
$$

then from (24) and (29), and having $R_{t}=R_{t+1}^{k}$,

$$
\begin{aligned}
& \hat{k}_{t+1}^{d}=-\frac{1}{1-\alpha} \hat{R}_{t+1}^{k} \\
& \hat{k}_{t+1}^{s}=-\frac{\alpha}{1-\alpha} \hat{R}_{t}^{k}+\hat{A}_{t}+\left[\ln \left(\frac{\beta_{R_{t+1}^{k}, \sigma}}{1+\beta_{R_{t+1}^{k}, \sigma}}\right)-\ln \left(\frac{\beta_{R^{*}, \sigma}}{1+\beta_{R^{*}, \sigma}}\right)\right]
\end{aligned}
$$


Equilibrium

$$
\begin{aligned}
\hat{k}_{t}^{d} & =\hat{k}_{t}^{s} \\
\hat{R}_{t+1}^{k} & =\alpha \hat{R}_{t}^{k}-(1-\alpha) \hat{A}_{t}-(1-\alpha)\left[\ln \left(\frac{\beta_{R_{t+1}^{k}, \sigma}}{1+\beta_{R_{t+1}^{k}, \sigma}}\right)-\ln \left(\frac{\beta_{R^{*}, \sigma}}{1+\beta_{R^{*}, \sigma}}\right)\right]
\end{aligned}
$$

Transition from one steady state to another. Initial steady state: at $t=t_{o}-1$ aging $A_{t_{o}-1}=A_{1}^{*}$ and $R_{t_{0}-1}=R_{1}^{*}=R_{t_{0}}$. At $t=t_{0}$ aging changes for a change in $g$ from $A_{1}^{*}$ to $A_{2}^{*}$. Define $\hat{A}^{*} \equiv \tilde{A}_{1}^{*}-\tilde{A}_{2}^{*}, \hat{R}^{k *} \equiv \tilde{R}_{1}^{k *}-\tilde{R}_{2}^{k *}$, and $\hat{R}_{t}^{k} \equiv \tilde{R}_{t}^{k}-\tilde{R}_{2}^{k *}$.

(i) $\sigma=1$ and $\delta=1$ :

$$
\begin{aligned}
\hat{R}_{t+1}^{k} & =\alpha \hat{R}_{t}^{k} \text { for } t \geq t_{0} \\
\hat{R}_{t}^{k} & =\alpha^{t-t_{0}} \hat{R}^{k *} \\
\tilde{R}_{t}^{k} & =\alpha^{t-t_{0}}\left(\tilde{R}_{1}^{k *}-\tilde{R}_{2}^{k *}\right)+\tilde{R}_{2}^{k *}
\end{aligned}
$$

$\alpha \in] 0 ; 1[$, the series converges monotonically to the new steady state. The sign of the convergence process is opposite to aging change. Note that if $\sigma=1$ then $\hat{R}^{*}=-\hat{A}^{*}$

$$
\tilde{R}_{t}^{k}=\tilde{R}_{1}^{k *}-\left(1-\alpha^{t-t_{0}}\right)\left(\tilde{A}_{2}^{*}-\tilde{A}_{1}^{*}\right)
$$

(ii) General case for $\sigma$ and $\delta \in] 0,1]$ : $\log$ linearizing (49),

$$
\begin{aligned}
\hat{R}_{t+1}^{k} & =\left(\alpha_{R^{k *, \sigma}}\right) \hat{R}_{t}^{k} \text { for } t \geq t_{0} \\
\hat{R}_{t}^{k} & =\left(\alpha_{R^{k *}, \sigma}\right)^{t-t_{0}} \hat{R}^{k *} \\
\tilde{R}_{t}^{k} & =\left(\alpha_{R^{k *}, \sigma}\right)^{t-t_{0}}\left(\tilde{R}_{1}^{k *}-\tilde{R}_{2}^{k *}\right)+\tilde{R}_{2}^{k *} \\
\text { where } \alpha_{R^{k *}, \sigma} & \left.=\alpha \frac{1+\beta_{R^{k *}}}{1+\beta_{R^{k *}}+(1-\alpha)\left(\frac{1}{\sigma}-1\right) \frac{R^{k *}}{R^{k *}+(1-\delta)}} \in\right] 0 ; 1[
\end{aligned}
$$

the series always converges monotonically to the new steady state. The sign of the convergence process is opposite to aging change. The convergence process takes longer for higher level of $\sigma$ and lower levels of $\delta$.

\section{F Aggregate Demand}

\section{(i) Consumption function}

From the Euler equation (10) and budget constraint of the old (16), and assuming full depre- 
ciation of capital in each period, $\delta=1$

$$
\begin{aligned}
C_{t} & =C_{t}^{y}+C_{t}^{o} \\
& =N_{t}^{y} \frac{s_{t}}{\beta_{R_{t}, \sigma}}+R_{t-1} N_{t}^{o} s_{t-1} \\
& =\frac{1}{1+\beta_{R_{t}, \sigma}}\left(w_{t} L_{t}-G_{t}\right)+R_{t}^{k} K_{t}^{s} \\
& =\frac{1}{1+\beta_{R_{t}, \sigma}}\left[(1-\alpha) Y_{t}-G_{t}\right]+\alpha Y_{t} \\
& =\left[\frac{(1-\alpha)}{1+\beta_{R_{t}, \sigma}}+\alpha\right] Y_{t}-\frac{1}{1+\beta_{R_{t}, \sigma}} G_{t}
\end{aligned}
$$

(ii) Investment function

$$
I_{t}=K_{t+1}=\alpha \frac{Y_{t+1}}{R_{t+1}^{k}}=\alpha \frac{Y_{t+1}}{R_{t+1}}
$$

(iii) Aggregate Demand

$$
\begin{aligned}
Y_{t} & =C_{t}+I_{t}+G_{t} \\
& =\left[\frac{(1-\alpha)}{1+\beta_{R_{t}, \sigma}}+\alpha\right] Y_{t}+\alpha \frac{Y_{t+1}}{R_{t+1}}+\frac{\beta_{R_{t}, \sigma}}{1+\beta_{R_{t}, \sigma}} G_{t}
\end{aligned}
$$

(iv) Aggregate Demand per capita

$$
y_{t}^{p c}=\left[\frac{(1-\alpha)}{1+\beta_{R_{t}, \sigma}}+\alpha\right] y_{t}^{p c}+\left(\frac{\alpha}{R_{t+1}}\right)\left[\frac{1}{A_{t}}\left(\frac{1+A_{t}}{1+A_{t-1}}\right)\right] y_{t+1}^{p c}+\frac{\beta_{R_{t}, \sigma}}{1+\beta_{R_{t}, \sigma}} G_{t}^{p c}
$$

(v) Aggregate Demand per capita in steady state

$$
y^{p c}=\left[\frac{1-\alpha}{1+\beta_{R, \sigma}}+\alpha+\frac{\alpha}{A} \frac{1}{R}\right] y^{p c}+\frac{\beta_{R, \sigma}}{1+\beta_{R, \sigma}} G^{p c}
$$

Assuming that the system is determined, and taking logs, $\tilde{y}^{p c}$ is expressed in terms of $R$ and $A$, when Government spending per capita is constant, and when it is proportional to full employment output:

$$
\begin{array}{ll}
\text { If } G^{p c}=\bar{G}^{p c} & \text { then } \tilde{y}^{p c}=-\ln \left[(1-\alpha) \frac{\beta_{R, \sigma}}{1+\beta_{R, \sigma}}-\frac{\alpha}{A} \frac{1}{R}\right]+\ln \left(\frac{\beta_{R, \sigma}}{1+\beta_{R, \sigma}} \bar{G}^{p c}\right) \\
\text { If } G=\mathcal{G} \bar{Y} & \text { then } \tilde{y}^{p c}=-\ln \left[(1-\alpha) \frac{\beta_{R, \sigma}}{1+\beta_{R, \sigma}}-\frac{\alpha}{A} \frac{1}{R}\right]+\ln \left(\frac{\beta_{R, \sigma}}{1+\beta_{R, \sigma}} \frac{1}{1+A}\left(\frac{\alpha}{R}\right)^{\frac{\alpha}{1-\alpha}}\right)
\end{array}
$$

Where $\bar{y}^{p c}=\bar{y} \frac{1}{1+A}=\frac{1}{1+A}\left(\frac{\alpha}{R}\right)^{\frac{\alpha}{1-\alpha}}$ is full-employment output per capita.

\section{G Impact of aging on output per capita at the ZLB}

We now assume that $i=0, \Pi=R=1$, and also that $\sigma=1$ without loss of generality. Then an increase in aging leads unambiguously to a decrease of output per capita, , when Government 
spending per capita is constant, and when it is proportional to full employment output:

$$
\begin{array}{ll}
\text { If } G^{p c}=\bar{G}^{p c} & \text { then } \frac{d y^{\tilde{p} c}}{d A}=-\left[(1-\alpha) \frac{\beta}{1+\beta}-\frac{\alpha}{A}\right]^{-1} \frac{\alpha}{A^{2}}<0 \\
\text { If } G=\mathcal{G} \bar{Y} & \text { then } \frac{d y^{\tilde{p} c}}{d A}=-\left[(1-\alpha) \frac{\beta}{1+\beta}-\frac{\alpha}{A}\right]^{-1} \frac{\alpha}{A^{2}}-\frac{1}{1+A}<0
\end{array}
$$

